\title{
INFLUÊNCIA DO INVESTIMENTO ANJO NA TOMADA DE DECISÃO E NOS PROBLEMAS DE AGÊNCIA: UM ESTUDO DE CASO'
}

DOI: $10.14211 / 41212$

Artigo recebido em: 13/11/2014.

Artigo aprovado em:14/11/2014.

\author{
Gustavo Simões Braga - Universidade Federal do Paraná2 \\ Kessyane da Silva Novaes Horbucz - Universidade Federal do Paraná \\ Ana Paula Mussi Szabo Cherobim - Universidade Federal do Paraná ${ }^{4}$
}

Resumo: Neste trabalho é analisado como a tomada de decisão dos investidores anjos afeta os conflitos de agência. O objetivo principal é entender, com base na Teoria da Agência, como o investimento anjo, a tomada de decisão de investimento e os agentes se relacionam, bem como identificar impactos positivos e negativos desta prática. Para isso, foram elaboradas proposições com o intuito de confirmar ou não tais conflitos de agência em uma empresa investida. A estratégia de pesquisa utilizada foi o estudo de caso, com seleção por representatividade qualitativa por ser um caso típico, a fim de analisar o investimento anjo na empresa Ecobike Courier. Como técnica de coleta de dados, foi realizada uma entrevista em profundidade com o sócio-fundador da empresa citada. Sendo assim, a participação na tomada de decisões por parte do investidor anjo é analisada com base nos problemas de agência, apontados por Damodaran (2002).

Palavras-chave: Investimento anjo, teoria da agência, tomada de decisão.

\section{ANGEL INVESTMENT INFLUENCE IN DECISION MAKING AND IN THE AGENCY PROBLEMS: A CASE STUDY}

Abstract: This study analyses how the influence of angel investors in decision-making affects the agency conflicts. The main objective is to understand, based on the Agency Theory, how these two elements are related and to identify positive and negative aspects. For this, the propositions were made to confirm or not the agency conflicts in the invested company. We used a case study methodology, with qualitative representation, to analyze angel investment in the company Ecobike Courier. As data collection technique, a depth interview has been made with de owner and founder of the company. Thus, the participation in decision-making by angel investors is analyzed with the agency problems pointed by Damodaran (2002).

Keywords: Angel investment, agency theory, decision making.

\footnotetext{
1 Artigo indicado por meio do Fast Track do SemeAd (2014)

2 E.mail: gustavosimoesbraga@gmail.com

${ }^{3}$ E.mail: kessy_ane@hotmail.com - Endereço: Av. Lothario Meissner, 632, 2ํandar - Jardim Botânico - Curitiba - PR, CEP: 80210-170.

${ }^{4}$ E.mail: anapaulamussi@ufpr.br
}

BRAGA, G. S.; HORBUCZ, K. S. N.; CHEROBIM, A. P. M. S. Influência do investimento anjo na tomada de decisão e nos problemas de agência: um estudo de caso. Revista de

Empreendedorismo e Gestão de Pequenas Empresas, v. 4, n. 1, 2015. 
Introdução

Os conflitos existentes entre acionistas de empresas e administradores encarregados de maximizar o retorno do capital investido têm despertado o interesse de pesquisadores. Mais de $40 \%$ das pesquisas realizadas sobre a Teoria da Agência, tanto no âmbito nacional quanto no internacional, sugerem que a redução de conflitos entre principais (acionistas) e agentes (administradores) seja mais estudada (ROCHA et al., 2012).

Esta relação de conflito ocasionada pela separação entre propriedade e controle de capital é claramente observada em sociedades por ações, onde o acionista não participa do gerenciamento da empresa (ARRUDA; MADRUGA; FREITAS JÚNIOR, 2008). Por outro lado, quando há maior envolvimento na administração por parte dos acionistas, os conflitos, de acordo com esta lógica, tendem a diminuir. Este é o caso de uma série de empresas que recebem capital de risco de investidores anjos.

Nessa linha, a proposta deste artigo é estudar a relação entre o apoio gerencial por parte de investidores anjos, a tomada de decisão e os conflitos de agência em empresas que estão em etapa inicial de financiamento.

O tema tem como justificativa o crescimento das atividades de capital de risco no Brasil em função de o país ter um ambiente favorável a esse tipo de investimento e a rápida expansão pelo mundo, no que se refere à Venture Capital (VC) e todas as modalidades que compõem essa indústria de capital de risco (ABDI, 2011).

O investimento anjo é uma modalidade de financiamento por capital de risco normalmente utilizada por startups (empresas nascentes em fase de arranque, geralmente inovadoras ou de base tecnológica, e que já possuem uma ideia ou projeto a ponto de serem comercializados) para financiar suas atividades (RAMADANI, 2009).

Segundo Spina (2013), uma particularidade desse tipo de investimento é que, além do capital liberado para a empresa, ocorre envolvimento do investidor nas decisões administrativas da empresa. Esta característica também é conhecida como 
smart money, o que proporciona ao empreendedor um aumento na expectativa de sobrevivência em relação a sua nova empresa.

Existem argumentos de que a participação dos investidores anjos nas tomadas de decisão pode auxiliar os novos gestores que não possuam muita experiência na gestão de empresas. Além do capital investido, os investidores costumam contribuir com uma vasta rede de contatos (MASON; HARRISON, 2002; MORRISSETTE, 2007). Por outro lado, a influência de uma pessoa que se ausenta muito em um negócio pode prejudicar o processo decisório.

A Teoria da Agência trata do conflito de interesses e assimetria de informações entre atores organizacionais. Isso pode acarretar problemas organizacionais, uma vez que uma das partes da empresa - o principal - delega as decisões que influenciam seus retornos financeiros à outra parte - o agente. Os interesses nem sempre são coincidentes e podem muitas vezes ser conflitantes (JENSEN; MECKLING, 1976).

Esta teoria afirma que problemas organizacionais ocorrem quando há divergência de objetivos entre duas partes: o principal, que detém parte do capital social da empresa, e o agente, que é o administrador da empresa. Isso ocorre quando o agente busca seus interesses próprios, como satisfação pessoal e maximização de benefícios, em detrimento dos objetivos do principal (GODOY; MARCON, 2006). Outro fator que causa esses problemas é a falta de monitoramento do principal sobre as ações do agente.

Assim, este estudo se inicia apresentando conceitos a respeito da teoria da firma e como eles podem ser aplicados neste contexto. Por ser uma questão de pesquisa que busca descrever como esse fenômeno ocorre, a metodologia empregada é a de estudo de caso único pela abordagem de Yin (2005).

A empresa analisada neste estudo de caso é a Ecobike Courier, uma empresa inovadora, localizada em Curitiba/PR, que se encontra em fase nascente, o que permite classificá-la como uma startup.

A atividade principal dessa empresa é o serviço de entrega, utilizando bicicletas como meio de transporte. Trata-se de um serviço inovador, pois esta é a primeira empresa nesse ramo a atuar em Curitiba/PR. Fato que chamou a atenção da imprensa local, a qual realizou várias matérias com a empresa estudada.

BRAGA, G. S.; HORBUCZ, K. S. N.; CHEROBIM, A. P. M. S. Influência do investimento anjo na tomada de decisão e nos problemas de agência: um estudo de caso. Revista de

Empreendedorismo e Gestão de Pequenas Empresas, v. 4, n. 1, 2015. 
Para financiar essa empresa inovadora, o seu fundador optou pelo investimento anjo. Atualmente, há um investidor que acreditou na ideia da empresa e aplicou seu capital com a expectativa de receber elevado retorno futuramente. Além do capital, o investidor também participa de algumas decisões administrativas da empresa. Esta relação é analisada com base na Teoria da Agência.

\section{Referencial teórico}

Para que esse tema possa ser compreendido, é necessário o resgate de alguns conceitos. $O$ entendimento do conceito de principal e agente, capital de risco, além de startups e investidores anjos.

O capital de risco, também chamado de venture capital, "amplia o fomento ao empreendedorismo, incentiva 0 surgimento de novas empresas e o desenvolvimento tecnológico interno, concorre para a retenção dos talentos no país e cria novos empregos" (BAÊTA; BAÊTA-LARA; MELO, 2006, p. 02).

Segundo Luna, Moreira e Gonçalves (2008), o capital de risco contempla diferentes perfis de investidores, sendo que um deles são os chamados anjos e, por participar na gestão dos projetos, reduzem as probabilidades de erros e, consequentemente, aumentam a possibilidade de maior retorno do capital investido.

Por isso, no que se diz respeito ao angel capital ou capital anjo, este é uma modalidade de capital de risco voltada a empresas em fase de ideia embrionária (protótipo), com um produto ou serviço escalável, conforme Macht e Robinson (2009)

Uma das razões que faz com que os empreendedores e suas startups busquem por capital anjo é o fato de que os investidores anjos já possuem um perfil de gestão, habilidades de negociação e rede de contatos, proporcionando ao empreendedor possibilidade de expansão e evitando mortalidade precoce de sua empresa.

Dessa forma, investimento anjo é uma importante fonte de financiamento direcionado a empresas jovens, as quais não possuem garantias suficientes para atrair os fundos formais (RAMADANI, 2009). 
perfil de investidor anjo é composto, em geral, por pessoas físicas que investem recursos próprios. O capital varia entre US\$50 mil e US\$500 mil. Ademais há maior proximidade com a empresa e troca de experiências entre os investidores e gestores da empresa (ABDI, 2011).

As Startups podem ser definidas como empresas em fase de estruturação, geralmente no primeiro ou segundo ano de funcionamento. Nesse estágio de desenvolvimento, o investimento anjo costuma ser utilizado para desenvolvimento de produtos e marketing inicial (ABDI, 2011). De acordo com Spina (2013), a maioria dos investidores anjos procura por startups com elevado potencial de escalabilidade, ou seja, a capacidade de aumentar a carteira de clientes e do faturamento, sem a necessidade de ampliar o capital humano ou infraestrutura para atender o aumento da demanda.

As decisões de financiamento, inclusive as relativas às startups, são fundamentadas pela teoria da estrutura de capital. Uma das teorias mais discutidas nesta área é a Teoria da Agência (KAYO; FAMÁ, 1997).

De acordo com a Teoria da Agência de Jensen e Meckling (1976), o agente é um profissional autorizado por outra pessoa, denominado principal, a agir em seu interesse. Sendo assim, um gerente de empresa que possua menos de $100 \%$ da empresa é considerado um agente dos outros proprietários.

A divergência de interesses que podem existir entre principal e agente acarreta em um conflito de interesses, surgindo a necessidade de mecanismos de controle do agente por parte do principal, que representará os custos de agência (SEGATTO-MENDES, 2001).

No caso das empresas que recebem capital anjo, normalmente o administrador é quem teve a ideia inicial e fundou a empresa (sócio-fundador). Em geral, os investidores são grupos de indivíduos com larga experiência executiva.

Estes investidores anjos depositam capital na empresa e delegam as funções administrativas aos gestores, prestando auxílio na tomada de decisão. De acordo com Bruton et al. (2010), o investimento anjo pode ser classificado com um investimento informal de capital de risco, já que ele é realizado sem a constituição de um fundo formal de investimento. 
Segundo Aernoudt (1999), a relação entre investidor anjo e empreendedor deve ser vista como um "casamento", onde existe a fase da prospecção e, posteriormente, a fase da convivência e conflitos de ideias. Assim, para que essa relação perdure, é importante o empreendedor entender que o investidor não é um filantropo, mas uma pessoa que oferece conhecimento empírico ao empreendedor, visando afastar ao máximo as "armadilhas" que possam surgir no novo empreendimento.

Pode-se considerar, portanto, que há existência da relação de principal (investidores anjos, acionistas que delegam funções administrativas) e agente (gestores, que têm funções administrativas e detêm menos de 100\% da empresa) na empresa estudada neste trabalho.

Esta relação é exemplificada por Damodaran (2002), que cita a possibilidade de um grande acionista da empresa ser também o diretor-presidente, como no caso de Bill Gates na Microsoft.

De acordo com esse autor, a Teoria da Agência prevê a possibilidade do surgimento de conflitos de interesses entre acionistas, pois nem sempre o administrador tem como objetivo principal a maximização da riqueza dos acionistas.

Os administradores podem estar, por exemplo, com o foco em garantir seus empregos. Com isso, podem priorizar projetos menos arriscados em detrimento a projetos que resultam em melhor relação de risco e retorno. A maior participação do principal nas decisões pode diminuir a ocorrência de conflitos de agência, pois uma das maneiras de diminuir os problemas de agência é aumentar o grau de monitoramento das decisões do administrador.

Outro ponto que pode aproximar os interesses do administrador nas empresas que recebem investimento anjo é que os próprios administradores possuem uma parcela considerável do capital da empresa.

Apesar desses dois aspectos, ainda assim existirão conflitos de agência que se devem às diferenças das funções de cada participante neste processo de financiamento por capital de risco.

Os problemas causados pelos conflitos de agência, segundo Damodaran (2002), são basicamente: 
1.Agentes seguirem seus próprios interesses - que podem ser maiores salários e benefícios ou segurança no emprego;

2. Expropriação de recursos da empresa;

3. Assimetria de informação entre os atores organizacionais.

Dos instrumentos de controle que podem ser criados para minimizar tais problemas, os mecanismos de controle externo podem ser considerados os mais eficazes. No entanto, em algumas modalidades de organizações, como as organizações sem fins lucrativos, tais mecanismos não têm o mesmo desempenho (ECCO et al., 2010). De forma análoga, pode-se afirmar que nas organizações caracterizadas pela relação entre investidores anjos e empreendedores, os mecanismos de minimização dos conflitos de agência também devem ser reavaliados.

Existem várias maneiras de minimizar a probabilidade de ocorrência e os impactos destes problemas. Algumas delas são:

1. Agentes portarem ações ou opções;

2. Agentes terem medo de substituição (geralmente decidida em assembleia geral ou conselho de administração);

3. Agentes serem disciplinados pelos principais;

4.Principais se protegerem de alterações repentinas na estrutura de capital por meio de cláusulas contratuais;

5.Fornecimento de informação suficiente e verdadeira para o mercado sobre o desempenho da empresa;

6. Fornecimento de informação suficiente e verdadeira sobre o trabalho dos agentes;

7.Um grande acionista participativo na empresa;

8. Acionistas mais ativos; $\mathrm{e}$

9.Número reduzido de pessoas no conselho de administração. 
Apesar de haver formas de reduzir os problemas causados pela divergência de interesses, estas medidas são onerosas em qualquer circunstância, ou seja, existem os chamados custos de agência (SANTOS; KELM; ABREU, 2001).

Com base nas questões levantadas na Teoria da Agência, são declaradas as seguintes proposições:

Proposição 1 (P1): os conflitos de agência tendem a diminuir em empresas que receberam capital de investidores anjos, pois os agentes possuem um percentual relevante da participação societária e com isso, seus interesses são mais parecidos com os dos principais.

Proposição 2 (P2): os conflitos de agência tendem a diminuir em empresas que receberam capital de investidores anjos, pois os principais costumam participar mais ativamente na administração da empresa e possuem um número reduzido de pessoas.

Proposição 3 (P3): por outro lado, os conflitos de agência podem aumentar em empresas que receberam capital de investidores anjos, pois os agentes dificilmente são substituídos da administração da empresa pelos principais. Isso ocorre em razão do seu elevado percentual na participação societária.

Assim, a proposta deste estudo é analisar empiricamente as proposições, considerando as particularidades do investimento anjo.

\section{Procedimentos metodológicos}

O estudo é qualitativo e classifica-se como analítico, cuja questão de pesquisa é: como a influência por parte dos investidores anjos nas tomadas de decisão afeta os conflitos de agência?

A estratégia de pesquisa é a de estudo de caso, com base em Yin (2005), por buscar responder uma questão de pesquisa descritiva e complexa que demanda aprofundamento na coleta e análise de dados.

Por ser um estudo de caso, optou-se em utilizar como técnica de coleta de dados primários a entrevista, conforme Marconi e Lakatos (2009). Em uma conversa frente a frente, o entrevistado tem a tendência de dialogar mais, expondo verbalmente informações ao pesquisador. 
Para que a entrevista forneça dados completos e, principalmente, por ser individual, é importante que seja realizada uma entrevista em profundidade. Desta maneira, optou-se por entrevistar o sócio-fundador de uma empresa, haja vista que ele tem visão de todo o cenário, anterior e posterior ao investimento. Assim, o entrevistado teve condições de contribuir com a sua percepção de conflitos, quando da entrada de um sócio-investidor. Hair et al. (2005) destacam que essa modalidade de entrevista proporciona uma discussão arraigada entre pesquisador e sujeito da pesquisa.

A empresa estudada é a Ecobike Courier, que recebeu investimento anjo há dois anos e, portanto, já tem uma percepção sobre como o auxílio na tomada de decisão por parte dos investidores influencia os conflitos de agência.

A empresa escolhida tem as seguintes características:

- Empresa que recebeu investimento anjo há pelo menos dois anos;

- $\quad$ Capital investido entre US\$50 mil e US\$500 mil;

- Há participação dos investidores anjos nas decisões da empresa.

Estas características, somadas a outros aspectos da empresa permitem afirmar que ela representa qualitativamente a população, apesar de estar em funcionamento há mais de dois anos. Entretanto, este fato permite avaliar com mais clareza a relação entre agente e principal, visto que este não é um relacionamento recente.

Os métodos de coleta de dados consistem em realizar entrevistas com o agente da empresa, ou seja, o empreendedor que a fundou e é responsável pela sua administração. Justifica-se a escolha do empreendedor porque tem 0 conhecimento tácito das alterações, positivas e negativas, decorrentes do aporte do capital anjo.

As entrevistas são semiestruturadas, seguindo o método de Entrevista Focal (MERTON; FISKE; KENDALL, 1990), na qual as perguntas são espontâneas, mas há um conjunto que deve ser seguido.

BRAGA, G. S.; HORBUCZ, K. S. N.; CHEROBIM, A. P. M. S. Influência do investimento anjo na tomada de decisão e nos problemas de agência: um estudo de caso. Revista de 
Análise dos dados

Aqui estão apresentados os resultados das entrevistas focais (MERTON; FISKE; KENDALL, 1990) realizadas com o administrador da empresa - portanto, o agente - com base no seguinte questionário semiestruturado, descreve-se as seguintes proposições com as devidas análises utilizando a teoria da agência:

Proposição 1 (P1): os conflitos de agência tendem a diminuir em empresas que receberam capital de investidores anjos, pois os agentes possuem um percentual relevante da participação societária e com isso, seus interesses são mais parecidos com os dos principais.

Conforme Corder e Salles-Filho (2006), a decisão do investidor é sempre deliberada na avaliação do risco versus retorno e por isso, esse investidor apenas assumirá mais riscos se houver a perspectiva de maior retorno. No caso de startups, o risco é relativamente maior.

O agente entrevistado esclareceu:

\begin{abstract}
Somos duas pessoas, em algum momento alguém vai ter que ceder para chegar a um acordo. Então, dificilmente nós saímos sem um acordo definido das nossas reuniões. Ele aponta o lado dele, eu aponto o meu, e nós verificamos qual é a melhor opção. Mas como eu vivo o negócio há três anos, teoricamente, quando o assunto é o negócio, a minha palavra tem um peso maior. Mas quando o assunto é estratégia, é algo que ele (investidor) pode me auxiliar, porém eu também tenho que observar se o ponto de vista dele é correto. $E$ temos nos acertado muito bem nesses aspectos.
\end{abstract}

$\mathrm{Na}$ entrevista percebeu-se que os conflitos tendem a diminuir, pois os sócios demonstram os mesmos interesses e objetivos de sucesso para a empresa, pelo fato de que a maximização dos lucros e a expansão dos negócios são benéficas para ambos.

Conforme Bruton et al. (2010), os investidores anjos são mais dependentes de governança relacional, procuram ser mais pacientes quando comparados a outros capitalistas de risco, além de serem mais preocupados com o controle.

Essa relação é explicada em razão de que o investidor anjo, neste caso, representado pelo principal, só obtém seu retorno do capital investido no momento de sua saída. Isso faz com que o principal participe ativamente da gestão para que BRAGA, G. S.; HORBUCZ, K. S. N.; CHEROBIM, A. P. M. S. Influência do investimento anjo na tomada de decisão e nos problemas de agência: um estudo de caso. Revista de 
essa empresa aumente o seu valor junto ao mercado e quando isso ocorrer, é provável ele venda a sua parte já multiplicada a terceiros, podendo assim continuar o ciclo de investimentos em outras empresas.

Da mesma maneira, o agente tem como objetivo a valorização da empresa, tanto para um aumento do seu patrimônio pessoal, quanto para que a empresa possa colocar em prática seus planos de expansão. Esta posição do agente é corroborada pelo seu discurso, já que no momento da entrevista cogitava uma possível venda de uma parcela de suas ações em algumas unidades da empresa.

Ele afirma durante a entrevista que não tem apego ao negócio e que o criou para vender no futuro. Com este pensamento, o agente se classifica como um "empreendedor em série", pois "vende uma empresa, abre outra, fecha uma, abre outra e assim vai”. Portanto, quanto mais se valorizarem suas ações, maior será o retorno sobre o capital investido.

Conclui-se que, tanto o principal quanto o agente possuem como interesse a valorização da empresa. Por esta razão, observa-se uma coerência nos interesses das duas partes devido ao modelo de financiamento optado, o que reduz os conflitos de agência.

Proposição 2 (P2): os conflitos de agência tendem a diminuir em empresas que receberam capital de investidores anjos, pois os principais costumam participar mais ativamente da administração da empresa, possuindo um número reduzido de pessoas que fazem parte do conselho.

De acordo com Johson e Sohl (2012), as empresas iniciantes, com capital humano e rede de contatos reduzida, possuem um risco de mortalidade maior que as empresas já consolidadas no mercado. Contudo, no momento em que um investidor com experiência e rede de contato desenvolvida é inserido na nova empresa, o cenário é beneficamente alterado.

Corroborando esta ideia, Ramadani (2009) afirma que muitos desses investidores anjos têm experiência no negócio e durante suas carreiras fizeram amizades com empreendedores e executivos de sucesso, banqueiros, contadores, entre outros.

BRAGA, G. S.; HORBUCZ, K. S. N.; CHEROBIM, A. P. M. S. Influência do investimento anjo na tomada de decisão e nos problemas de agência: um estudo de caso. Revista de 
No entanto, o entrevistado afirmou que o principal não possui tanta experiência no ramo da startup estudada, o que não anula as outras características já citadas pelos autores, pois o principal possui know-how estratégico e jurídico, rede de contatos e infraestrutura para treinamento da equipe e franqueados.

Notou-se que na entrevista com o empreendedor (agente), os conflitos tendem a diminuir quando há proximidade do principal com o agente, haja vista que uma das características principais do investidor anjo (principal) é a proximidade física que ele tem com o investido/empreendedor (agente).

Bruton et al. (2010) explica que uma das características dos investidores anjos é a preocupação com os risco de agência, pois enquanto investidores de outras modalidade se preocupam com o risco de mercado e com o retorno expansivo aos seus cotistas, o investidor anjo trabalha na base da confiança e da empatia com o empreendedor.

Neste caso, ocorrem encontros quinzenais que proporcionam a redução da assimetria de informações, pois o principal é constantemente informado sobre os resultados de negócios. Nessas reuniões, de acordo com o agente, os temas estratégicos são debatidos e as decisões são tomadas em conjunto.

A empresa estudada também segue outros princípios de governança corporativa, conforme elementos apontados pelo IBGC (2007). Além das reuniões quinzenais, são enviadas informações completas e fundamentadas, como Demonstrações de Resultado do Exercício (DRE) e balanços patrimoniais, de forma transparente e segura. Além disso, é minimizada a expropriação de recurso da empresa, uma vez que o principal tem um controle mais próximo da empresa, ainda que em nível estratégico.

Proposição 3 (P3): por outro lado, os conflitos de agência podem aumentar em empresas que receberam capital de investidores anjos, pois os agentes dificilmente são substituídos da administração da empresa pelos principais. Isso ocorre em razão do seu elevado percentual na participação societária.

Conforme explanado por Damodaran (2004):

Quando um banco ou um investidor empresta dinheiro para uma empresa, os investidores em patrimônio líquido continuam a controlar a empresa e a

BRAGA, G. S.; HORBUCZ, K. S. N.; CHEROBIM, A. P. M. S. Influência do investimento anjo na tomada de decisão e nos problemas de agência: um estudo de caso. Revista de

Empreendedorismo e Gestão de Pequenas Empresas, v. 4, n. 1, 2015. 
tomar decisões sobre investimento e financiamento. Em seus papéis como administradores da mesma, os investidores em patrimônio líquido estão agindo como agentes para os financiadores. No entanto, não irão concordar sempre sobre o melhor curso de ação para uma empresa, em grande parte porque têm diferentes direitos sobre o fluxo de caixa. (DAMODARAN, 2004, p. 449).

Não obstante, essa proposição não se confirma, visto que o interesse de aumentar o valor da empresa como prioridade é comum entre o principal e o agente. De acordo com o agente entrevistado, as metas estratégicas são sempre definidas em conjunto com o principal, sendo que seu monitoramento é realizado de forma recorrente. Nessa linha, o entrevistado reafirmou:

Nós nos reunimos a cada 15 dias. E temos uma pauta de decisões a serem tomadas pelos próximos 15 dias posteriores. Isso, consequentemente, torna a nossa relação mais tranquila e a prestação de contas é bem transparente, com a apresentação de todos os relatórios importantes durante esses encontros.

Por esse motivo, apesar de o agente ter a possibilidade de direcionar a empresa para os seus interesses, o fato de saber que não será substituído, de acordo com as respostas do agente, não influencia os conflitos de agência. $O$ entrevistado, inclusive, manifestou o interesse em concretizar novas ideias, com expectativa de abrir novas empresas e quem sabe se tornar um investidor anjo daqui alguns anos, já que ele almeja aumentar seu capital e terá certa experiência no que se refere a essa relação empreendedor versus investidor.

O agente tem consciência que pode ser substituído da empresa, mas isso não é motivo de conflito. Se essa substituição chegar a acontecer será por venda de suas ações ou de alguma fusão que, segundo o entrevistado, faz parte do mercado e sinaliza que a empresa está sendo valorizada.

Portanto, não foram encontrados elementos, durante a entrevista, que reforcem a proposição de que os conflitos de agência aumentarão devido à baixa probabilidade de substituição do gestor. 


\section{Considerações finais}

Neste trabalho buscou-se entender, com base na Teoria da Agência, como o investimento anjo, a tomada de decisão de investimento e os agentes se relacionam, bem como identificar impactos positivos e negativos desta prática. Foi possível realizar o estudo e avaliar as proposições, para analisar os conflitos de agência entre agente e principal em uma startup que tivesse sido financiada por uma modalidade de capital de risco, denominada de investimento anjo.

Os principais resultados demonstraram que os conflitos de agência entre principal e agente são reduzidos em razão de ambos buscarem a consolidação e expansão da empresa no mercado. Outro fator responsável pela redução dos conflitos é a proximidade do principal com o agente, uma das características principais do investimento anjo.

O agente enfatizou que, pelo fato de ter mais experiência que o principal nas atividades e no ramo de negócio da empresa estudada, detém mais credibilidade para tomar decisões operacionais por conta própria, tais como, contratar fornecedores e administrar o quadro de colaboradores. Porém, quando a tomada de decisão envolve o patrimônio da empresa como, por exemplo, lançar novos serviços ou expandir a empresa, o principal participa ativamente (isso se deve ao contrato firmado entre ambos no momento em que o aporte foi realizado) com o agente, cada qual utiliza seus argumentos até que se chegue a um acordo, sem aborrecimentos, conforme relatado pelo entrevistado.

Constatou-se que, em razão de o principal ser um investidor anjo e com isso estar presente nas decisões da empresa, houve uma diminuição do conflito na relação pertinente com o agente, no que se refere às tomadas de decisões sobre a empresa estudada. Esse fato relevante é resultante das cláusulas contratuais acordadas, pois ficaram definidas quais decisões e a quem as caberia tomar.

O investimento anjo é, portanto, uma alternativa para minimizar os problemas e custos de agência em empresas devido às suas características de proximidade de interesses entre agente e principal. De acordo com Bruton et al. (2010), os investidores buscam construir e manter um bom relacionamento com os investidos, 
tendem a se envolver mais com o empreendimento, objetivando, assim, garantir um maior desempenho da empresa aportada.

Espera-se que, diante das proposições apresentadas e respondidas, o caso contribua academicamente, estimulando os pesquisadores a levantar novos questionamentos sobre a rica relação entre investidores e empreendedores. Empiricamente, este estudo visa alcançar os empreendedores e investidores que ainda carregam dúvidas sobre o investimento anjo, assim como a forma como os investidores se relacionam com os investidos.

Diante do exposto, sugere-se para pesquisas futuras, que um estudo seja realizado com maior número de casos e que o fenômeno também seja analisado por meio de análises quantitativas.

\section{Referências:}

ABDI - Agência Brasileira de Desenvolvimento Industrial. A indústria de private equity e venture capital: $2^{\circ}$ censo brasileiro. Brasília: ABDI, 2011. (caps. 1 - 4).

AERNOUDT, R. Business Angels: should they fly on their own wings. Venture Capital, 1999, v. 1, n. 2, p. 187-195, 1999.

ARRUDA, G. S.; MADRUGA, S. R.; FREITAS JÚNIOR, N. I. A governança corporativa e a teoria da agência em consonância com a controladoria. Revista de Administração da UFSM, v. 1, n. 1, p. 71-84, 2008.

BAÊTA, A. M. C.; BAÊTA-LARA, F. M. C.; MELO, V. S. Financiamento da inovação: uma estratégia competitiva. Revista Administração em Diálogo, v. 8, n.1, p. 1-12, 2006.

BRUTON, G. D.; FILATOTCHEV, I.; CHAHINE, S.; WRIGHT, M. Governance, ownership structure, and Performance of IPO firms: the impact of Different types of private equity investors and institutional environments. Strategic Management Journal, v. 31, n. 5, p. 491-509, maio 2010.

CORDER, S.; SALLES-FILHO, S. Aspectos conceituais do financiamento à inovação. Revista Brasileira de Inovação, v. 5, n. 1, jan/jun, 2006.

DAMODARAN, A. Finanças corporativas aplicadas. Porto Alegre: Bookman, 2002.

Finanças corporativas: teoria e prática. Porto Alegre: Bookman, 2004.

BRAGA, G. S.; HORBUCZ, K. S. N.; CHEROBIM, A. P. M. S. Influência do investimento anjo na tomada de decisão e nos problemas de agência: um estudo de caso. Revista de

Empreendedorismo e Gestão de Pequenas Empresas, v. 4, n. 1, 2015. 
ECCO, I. L.; RIBEIRO R.; KOCK K. F.; MARCON R.; ALBERTON, A. Teoria De Agência Em Uma Organização Sem Fins Lucrativos. Estratégia e Negócios, Florianópolis, v. 3, n. 1, jan./jun. 2010.

GODOY, P.; MARCON, R. Teoria da Agência e os conflitos organizacionais: a influência das transferências e das promoções nos custos de agência em uma instituição bancária. Revista de Administração Mackenzie, v. 7, n. 4, p. 168-210, 2006.

HAIR JR., J. F.; BABIN, B.; MONEY, A. H.; SAMUEL, P. Fundamentos de métodos de pesquisa em administração. Porto Alegre: Bookman, 2005.

IBGC (2007). Instituto Brasileiro de Governança Corporativa. Código de conduta do IBGC. São Paulo: IBGC, 2007.

JENSEN, M. C.; MECKLING, W. H. Theory of Firm: Managerial Behaviour, Agency Costs and Ownership Structure. Journal of Financial Economics, v. 3, n. 4, p. 305360, out. 1976.

JOHNSON, C.W.; SOHL. J. Angels and venture capitalists in the initial public offering market. Venture capital, v. 14, n. 1, p. 27-42, 2012.

KAYO, E. K.; FAMÁ, R. Teoria de agência e crescimento: evidências empíricas dos efeitos positivos e negativos do endividamento. Caderno de Pesquisas em Administração, v. 2, n. 5, p. 1-8, set. 1997.

LUNA, F.; MOREIRA, S.; GONÇALVES, A. Financiamento à inovação. In.: DE NEGRI, J. A.; KUBOTA, L. C. Políticas de Incentivo à Inovação Tecnológica no Brasil. Brasília: IPEA, 2008.

MACHT, S.A; ROBINSON, J. Do Business angels benefit their investee companies? International Journal of Entrepreneurial Behavior \& Research, v.15, n.2, p.187208, 2009.

MARCONI, M. A.; LAKATOS, E. M. Metodologia do trabalho científico. 7 ed. São Paulo: Atlas, 2009.

MASON, C. M.; HARRISON, R. T. Barriers to investment in the informal venture capital sector. Entrepreneurship \& Regional Development, v.14, n. 3, p. 271 - 287, 2002.

MERTON, R. K.; FISKE, M.; KENDALL, P. L. The focused interview: A manual of problems and procedures. 2 ed. NewYork: FreePress, 1990.

MORRISSETTE, S. G. A Profile of Angel Investors. The journal of private equity, v. 10, n. 3, p. 52- 66, 2007.

BRAGA, G. S.; HORBUCZ, K. S. N.; CHEROBIM, A. P. M. S. Influência do investimento anjo na tomada de decisão e nos problemas de agência: um estudo de caso. Revista de

Empreendedorismo e Gestão de Pequenas Empresas, v. 4, n. 1, 2015. 


\section{A Revista da ANEGEPE \\ www.regepe.org.br}

RAMADANI, V. Business angels: who they really are. Strategic Change, v.18, n. 78, p. 249 - 258, nov. 2009.

ROCHA, I.; PEREIRA, A. M.; BEZERRA, F. A.; NASCIMENTO, S. Análise da produção científica sobre teoria da agência e assimetria da informação. Revista de Gestão, v. 19, n. 2, p. 227-340, 2012.

SANTOS, J. L. D.; KELM, M. L.; ABREU, A. F. Um modelo de gestão por resultados segundo a teoria da agência - um estudo de caso: Banco do Estado de Santa Catarina S.A. Revista de Administração, v. 36, n. 3, p. 59-69, 2001.

SEGATTO-MENDES, A. P. Teoria de agência aplicada à análise de relações entre os participantes dos processos de cooperação tecnológica universidadeempresa. São Paulo, 2001.

SPINA, C. A. Investidor anjo: Como conseguir investimento para o seu negócio. São Paulo: Ed. Nversos, 2013.

YIN, R. K. Estudo de caso: planejamento e métodos. 3 ed. Porto Alegre: Bookman, 2005. 